\title{
El desengaño del Estado
}

José Rodríguez Angulo

Universidad de Concepción, Chile

E-mail: josemrodriguez@udec.cl

\section{Resumen}

El texto deAlonso G onzález deN ájera D esen gaño y reparo delas guerras de C hile (escrito en 1608) busca explicar las causas de la excesiva prolongación de la guerra de Arauco y una vez determinadas propone una solución para terminar con la guerra y, de paso, con los araucanos. El ensayo que sigue muestra que $N$ ájera es capaz de percibir que la causa basal de la prolongación del conflicto es un problema estratégico. Para nosotros, en otrostérminos, tal problema es que se enfrentaban dos máquinas de guerra de muy distinto signo: una estatal y la otra nómada. D eahí que en un primer momento nuestro estudio exponga la teoría que distingue entre ambos aparatos bélicos, luego se interna en mostrar cómo la máquina india cabe dentro de la categoría nómada, de acuerdo a las noticias proporcionadas por $\mathrm{N}$ ájera, para finalmente discutir sobre la solución que éste propone al conflicto.

Palabras claves: M áquina, guerra, Estado, nomadismo.

\section{Abstract}

The text $D$ esen gaño y reparo de las guerras de C hile by Alonso G onzález de N ájera (written in 1608) search for the reasons behind the excessive prolongation of theA rauco war. O nce these reasons areestablished, thetext propposesa solution to en ding thewar, the Araucano people being part of that solution. According to $\mathrm{N}$ ajera, a estrategic problem is critical reason for the conflict extension: The Spanish force was badly distributed over the fields. For us and in another sense thetwo conflicting war machines had rather different features: A state on one hand; a nomadic machine on the other. Therefore, in this work we first describes thetheory that establishesthedifferences between both war machines. Secondly, we intentend to show that theindian belongs to thenomad category. Finally, we argue on the solution $\mathrm{N}$ ajera suggest to the conflict.

Keywords: M achine, war, State, nomadism.

Recibido: 16-06-2004. Aprobado: 25-06-2004.

II ECCIO N ES de una amarga experiencia". Así define el diccionario a la palabra desengaño, voz que inaugura un texto ejemplar de Alonso G onzález de N ájera (1971)ํ. La amarga experiencia es el fracaso sufrido por los súbdi-

${ }^{1}$ Texto original escrito en 1608. 
tos españoles en su intento de dominar, a través de la guerra, a los hombres sin rey de la tierra del sur, los araucanos.

Pensamos e intentaremos mostrarlo, que la causa basal de tal fracaso fue la insuficiencia de la máquina de guerra estatal, la española, para someter a una máquina de guerra nómada, la araucana. Esta diferencia es percibida por $\mathrm{G}$ onzález de Nájera, aunqueno en estos términos, ya queel autor anota la imposibilidad de la conquista si se continúa desarrollando la guerra sin variaciones sustantivas. M ostrado el problema, el texto sostiene que el Imperio debe desarrollar una estrategia distinta a la imperante para poder sumar esos cuerpos y la tierra a que pertenecen a los dominios de la cristiandad. Antes de exponer esa estrategia, nos interesa referir o desarrollar los conceptos que originan la distinción entre los aparatos bélicos estatales y nómadas. Luego, veremos si es posible extrapolar la diferencia a las máquinas de guerra que se opusieron en Arauco. Finalmente expondremos la solución que el autor del D esen gaño... sugiere para que España pueda ganar, de una vez por todas, esa guerra, esas tierras y esos hombres.

La diferencia entre máquinas nómadas y estatales se la debemos a la filosofía contemporánea, específicamente a D el euze-G uattari, este "autor" expone en su Tratado de nomadología (D eleuze y Guattari, 1997: 359-431) otra versión de la M áquina de Guerra. Pensamos quetal versión lefue sugerida al "teórico" por su lectura de "La construcción de la muralla C hina" deFranz Kafka. En este relato un funcionario menor, al parecer un albañil, narra los métodos que siguió el C eleste Imperio en la construcción de esa muralla inverosímil. Durante la faena, los obreros observaban que las tribus nómadas cruzaban frente a las obras para luego perderse en las estepas. El cronista anota que quizás los nómadas tenían una mejor visión dela muralla que los mismos constructores y albañiles.

La lectura anterior indica la presencia de dos aparatos: El uno, estatal, que intenta a todo al canc estriar el espacio, limitarlo (limes: muralla). El otro, nómada, que se mueve por un espacio abierto. Esta diferencia es la misma que D eleuze y Guattari usa para construir la genealogía de la máquina de guerra. (M áquina, en la teoría usada, es un sistema de cortes, corta flujos. U na máquina produce un determinado flujo que esa máquina u otra corta).

La máquina de guerra, en general, es un curioso "agenciamiento", cuyo fin, curiosamente, no es la guerra, sino ocupar un espacio tiempo. Su origen lo encontramos en "Ia consecuencia necesaria dela organización nómada" (D eleuze y Guattari, 1997: 395). Sugiere así, el Tratado de nomadología, que aquella máquina tiene un origen nómada, luego lo confirma: "La máquina de guerra en sí misma parece claramente irreductible al aparato del Estado, exterior a su soberanía, previa a su derecho. Tiene otro origen" (D eleuze y G uattari, 1997: 360). 
El carácter nómada de la máquina de guerra implica que todo lo viva en relaciones de devenir, al contrario de la máquina estatal que se estratifica constante. Ahora, ¿qué significa que todo lo viva en relaciones de devenir?

El devenir, para el "autor", es un lugar de flujo, un estar entre una cosa y otra, implica derrotar el binarismo y abandonarse en una corriente, un flujo... D evenir es, a partir delasformas que se tiene, del sujeto que sees, de los órganos que se posee 0 de las funciones que se desempeña, extraer partículas entre las que se instalan relaciones de movimiento y de reposo, de velocidad y de lentitud. En este sentido el devenir es "el proceso del deseo". Luego, la máquina de guerra está atravesada, en su interior, por todo tipo de estos devenires, dentro de ella los números, los hombres, que la componen devienen, por ejemplo, animal en el furor, hembra en la derrota. Exterior a ella, el devenir de la máquina se expresa en que "traza una línea de fuga creadora, la composición de un espacio liso y el movimiento de los hombres en ese espacio" (Rodríguez, 2002). Este párrafo contiene y perfila las características de la máquina de guerra en tanto invención nómada:

1. Un aspecto espacial geográfico.

2. Un aspecto aritmético.

3. Un aspecto afectivo.

1. Aspecto espacial geográfico: El nómada se desplaza por espacios lisos. Los trayectos determinan los puntos. Los nómadas se mueven o permanecen, en un lugar de la naturaleza que no está fijado por estrías o demarcaciones estables, sino que movimiento y permanencia están determinados por velocidades, intensidades, devenires. Estos hombres van de un lugar a otro como consecuencia de una necesidad de hecho, lo cual genera una distribución espacial de los suje tos en un espacio abierto no comunicante. Al contrario de los espacios sedentarios que son estriados por muros, lindes, el espacio nómada está marcado por trazos que se borran, irregulares. No olvidemos, a este respecto, que la comunicación es una de las obsesiones del Estado.

2. Aspecto aritmético: D ecíamos que la máquina de guerra es la consecuencia "necesaria de la organización nómada". D e aquí que su carácter sea esencialmente aritmético. Leemos: "Cuando G engis K han crea su gran composición de la estepa organiza numéricamente los linajes y los combatientes de cada linaje... " (D eleuzey G uattari, 1997: 395). En el mismo sentido observamos: "Cuando M oisés crea su gran composición del desierto, en la que más quela influencia deYahvé, sufre necesariamente la influencia nómada, recrea y organiza numéri- 
camente cada tribu... " (D eleuze y G uattari, 1997: 395). N otamos que, en origen, la máquina tiene un fin logístico, cual es, organizar el movimiento de un grupo de bandas, linajes o tribus, a través de un espacio.

3. Aspecto afectivo: Afectos, en la teoría que nos ocupa, significa algo así como provocar una conmoción en otro o en una cosa. El aspecto "afectivo" de la máquina de guerra está dado en que la existencia nómada tiene por afectos las armas, armas que proyectan la desterritorialización. El afecto es la descarga rápida de la emoción, de la respuesta. Los afectos son proyectiles tanto como las armas. D esde este punto devista, se puede combinar el paso del Estado inmóvil del guerrero a la velocidad pura, con la relación reposo-velocidad de la máquina de guerra.

Intentamos, ahora, aplicar los desarrollos anteriores a la máquina india. El devenir, por ejemplo, la recorre. G onzález de N ájera describe una fiesta de los guerreros donde "unos traen parte de vestidos de soldados españoles y otros hábitos religiosos... otros andan cubiertos con pieles de fieras con las cabezas boquiabiertas, que caen encima de las suyas mostrando grandes dientes... " (González de N ájera, 1971: 55). Se observa claramente un devenir animal en los guerreros.

En segundo lugar, respecto del carácter espacial geográfico de la máquina araucana leemos: "N o tienen los indios ciudades, villas o lugares para su habitación, ni fuertes, ni otro género de fortaleza fuera de la gran ciénaga de Purén que lo es por natural eza... ". O bservamos que los mapuches se mueven o viven en un territorio que no está delimitado por marcaciones estables, es decir, un espacio liso. Además se anota que la fuerza de los indios está en relación con la tierra, la cual no está "estriada", no existen poblados, ni fortalezas, a excepción de la ciénaga de Purén o la fortaleza de sus montes. La relación entre persona y tierra está determinada por una intensidad o una suma de ellas. Estas intensidades son tan fuertes como para crear un vínculo indisoluble entre los araucanos y la tierra. Ellos se encuentran, como observa la nomadología, "distribuidos en un espacio abierto, indefinido..." (D eleuze y Guattari, 1997: 385); tal y como observa $G$ onzález de N ájera a los indios del sur: "tienen distribuidas y apartadas sus habitaciones en diversos valles" (G ónzalez de N ájera, 1971: 48). El punto es de suyo relevante en el sentido que nos permite realzar un sema fundamental del nomadismo: aquel que indica que no necesariamente la categoría coincide con un elemento migratorio, pues "mientras que el migrante abandona un medio que ha devenido amorfo o ingrato, el nómada es aquel que no se va, que no quiere irse, que se aferra a ese espacio liso en que el bosque recula... " (D eleuze y Guattari, 1997: 385). En el mismo sentido G onzález de $N$ ájera anota que los 
"bárbaros" tienen "un singular amor a su patria, de la cual es cosa particular que no hay indio que no atreva a salir" (Gónzalez de Nájera, 1971: 50). No es que no se atrevan, de acuerdo al nomadismo la permanencia se debe a que en ese lugar han constituido un espacio tiempo. Luego, insiste que los mapuches, a pesar de vencer en la batalla y ufanarse de sus triunfos, "no se puede presumir que tengan ánimo o valor para dejar los límites de su reino" (Gónzalez de Nájera, 1971: 54). Ese "reino" es su espacio tiempo, de ahí que constantemente insistan en alisarlo, alisamiento que consiste pura y simplemente en destruir toda "estría", toda marca que limite la tierra. Al ejemplo se nos informa: "Asolaron las ciudades de Valdivia, La Imperial, La Villarrica, 0 sorno, y la de los Infantes de Angol" (G ónzalez de N ájera, 1971: 64).

En cuanto al aspecto aritmético de la máquina de guerra araucana, éste se puede observar en que la destrucción de las ciudades nombradas se dio en un momento en que estaban rebelados todos los Indios... Tal frase muestra que no siempre se levantaba un número o fracción determinados, lo cual indica que la máquina araucana es enteramente flexible, formada por guerreros, no por soldados que sólo son soldados. 0 tro ejemplo lo encontramos cuando los indios cobraron bríos tras unas sonadas derrotas infligidas a los españoles. En la ocasión: "no sólo crecen en ánimo sino también en número" (G ónzalez de Nájera, 1971: 79). Se observa, claramente, la presencia de un nomadismo aritmético, se suman indios a la máquina de guerra. En el mismo sentido leemos: "Estando en sus tierras, con facilidad ponen tregua a sus domésticas pasiones, y se reconcilian para juntarse contra los nuestros" (Gónzalez de N ájera, 1971: 79).

Finalmente, creemos que el aspecto afectivo de la máquina india se transparenta en el uso de un afecto esencial de la máquina de guerra, éste es el secreto, citamos: "Cómo degolló el enemigo la escolta del fuerte de la Imperial con el caudillo y dos capitanes, y el maravilloso secreto con que los enemigos tuvieron oculta la victoria" (G ónzalez de N ájera, 1971: 74). Esta referencia a la capacidad que tenían los araucanos para guardar en el más estricto secreto sus movimientos es destacada constantemente por el español. El secreto, entonces, es un arma.

Recordemos, en este punto, que iniciamos el presente estudio asignando un carácter nómada a la máquina de guerra araucana, atribución basada, fundamentalmente, en que los indios del sur eran un pueblo sin Estado. Por ende, aquella máquina no sólo posee las características generales del "agenciamiento" nombrado, sino que además la tribu a la que pertenece cumple con una categoría "cero" del nomadismo, esto es fundarse en una "nación" sin órganos². Baste

${ }^{2} \mathrm{C}$ ategoría que hace presente la diferencia polar entre lo nómade y lo estatal, pues el Estado es por esencia una institución sustentada por una suma de órganos judiciales, administrativos, legislativos, etc. 
señalar al respecto que en la primera página de El desengaño... se lee que los naturales al sur del Bío-Bío no tenían rey ni caudillo a quien obedecer.

Interesa, también, comentar un aspecto complejo de la máquina, cual es su fin. Como decíamos, la máquina de guerra intenta, fundamentalmente, componer un espacio de distribución. El objetivo de aquélla, entonces, no es la guerra, ésta aparece como un "suplemento"3. 0 más claramente, la máquina, "si pensamos en términos aristotélicos, mantiene una relación sintética con la guerra" (D eleuze y G uattari, 1997: 435). Un ejemplo aclarará este punto:

M oisés, en su éxodo, observa que la guerra es una posibilidad de su máquina, lo cual ciertamente constituyó una angustia para ese egipcio que mantenía tratos con un D ios. Será necesario luchar contra las ciudades y los Estados por los que se cruza. Es aquí, en este punto donde deviene la guerra para la máquina: D ebe aniquilar las fuerzas del Estado, debe destruir la forma Estado. D ebe alisar el espacio estriado por la soberanía estatal. En el mismo sentido trabajan los mapuches. Ya vimos cómo la máquina araucana alisa el espacio, por ende éste era su fin. La guerra aparecerá como "suplemento" de aquélla. Veamos la respuesta de los españoles al alisamiento: "Llegado el gobernador al sitio de la asolada Imperial, comenzó luego a un mismo tiempo a dar principio a las dos obras desu designio, que fueron la fundación del fuerte y rescate delas cautivas" (Gónzalez de N ájera, 1971: 68). H ombre de Estado clásico, frente a un hecho que no comprende, el nomadismo, sólo puede responder con la restitución del fuerte, el que poblará de soldados, es decir, configura una máquina cuyo objetivo único es la guerra. Y esta diferencia es fundamental: Los nómadas no tienen la guerra en su horizonte. Esta surge, puede surgir, como una necesidad de hecho en su devenir.

Volviendo a La Imperial, creemos que la reconstrucción del fuerte ordenada por el G obernador no tiene mucho futuro, pues la guarnición puede ser fácilmente destruida por una causa muy simple: la equivalencia, de campo, entre la máquina de guerra araucana y la máquina de guerra española, tesis que casi ningún civilizado sería capaz de admitir. D e hecho una inquietud que recorre las diversas crónicas escritas en el Reino es el por quéde la duración de la guerra, dada la enorme superioridad (desde la perspectiva europea) que tiene la máquina imperial respecto de la mapuche, ventaja que, sin embargo, era incapaz de plasmar en la realidad. Sostenemos que la razón de tal incapacidad es muy concreta. Leemos: "La relación entre la fuerza aplicada y la resistencia ofrecida por la carga contra la que actúa la fuerza se denomina ventaja teórica de la máquina.

${ }^{3}$ Entendido, este término, en el sentido que Jacques D errida le confiere. 
D ebido a que todas las máquinas deben superar algún tipo de rozamiento cuando realizan su trabajo, la ventaja real de la máquina siempre es menor que la ventaja teórica. La eficacia de funcionamiento de una máquina se obtiene del cuociente entre la energía generada (la salida) y la cantidad de energía empleada (la entrada). La eficacia, que se expresa en tanto por ciento, es siempre inferior al 100 por ciento" (Enciclopedia Encarta, 2003).

Creemos que en la relación anterior se puede encontrar una clave del por qué se hizo eterna de la guerra de Arauco: La ventaja teórica de la máquina estatal era anulada por ser muy al to el factor de roce que le oponía la máquina nómada.

Tal factor no consistía, por ejemplo, en la gran fortaleza de los araucanos como bien lo entiende González de N ájera cuando sostiene: "Los indios de Chile no son más robustos, membrudos ni de mayor al tura que nuestros españoles". En el mismo sentido anota: "Es verdad que se hallan entre los dichos indios al gunos de espal das grandes y pechos levantados, pero no en tanto extremo como al gunos se han persuadido" (Gónzalez de Nájera, 1971: 39 y 40). La percepción del autor desconstruye así la visión mítica del araucano que se había ido construyendo durante la guerra, visión mítica que no sólo operaba respecto de una versión superlativa de la fuerza de indio, sino que también a niveles sociales, los indios no son "gente gallarda", sino "viciosa"; dados al canibalismo, etc. C reemos que en todos estos acápites el autor está escribiendo "contra" La Araucana, la que aparece como el contratexto del D esengaño... , marcada la oposición en el sintagma "como algunos se han persuadido". Entre los "algunos" está Ercilla, el quellegó "donde ninguno ha llegado", es decir, un hombre "civilizado" que fue capaz de mostrar la igual dad e incluso la superioridad bélica del indio. Y que, por ende, equiparó teóricamentea la máquina araucana y española, equivalencia que para el $D$ esengaño... es imposible, pues para G onzález de N ájera el problema es sólo estratégico, como se verá.

A notemos ahora los factores de roce que el texto considera como aquellos que sí anulan la ventaja teórica del ejército imperial:

1. El primero está fijado en el accionar dela máquina de guerra araucana, ya que se destacan "las astucias, estratagemas y sagacidad con que hacen la guerra los indios a los nuestros" (Gónzalez de N ájera, 1971: 94). Aquí encontramos una aparente contradicción en G onzález deN ájera, pues los indios ha poco subnormales, aparecen como sagaces. Pensamos que tal contradicción está dada en virtud de que una característica crucial del Estado es que para sus hijos "la ori- 
ginalidad del hombre de guerra aparece bajo una forma negativa: estupidez, deformidad, locura, usurpación, pecado..." (D eleuze y Guattari, 1997: 361). Sujeto estatal como es el autor, no puede sino plegarse y, por ende, "ningunear" a todo aquel que no desee ser sirviente de esa cosa tan rara que los hombres construyeron para someterse a sí mismos, el Estado.

N osotros vemos que a pesar del plan del texto, se filtra en él la presencia de una "ciencia menor o nómada" (D eleuzey Guattari, 1997: 369). Un claro jemplo de ésta son las picas que construyen los indios: "Traen ellas por hierros pedazos de espadas españolas con amoladas puntas..." (Gónzalez de N ájera, 1971: 95). N otamos que los indios son capaces de perfeccionar un arma, adaptándola a las condiciones espacio-temporales de la guerra. Las espadas eran muy pesadas, lentas. Fraccionarlas en partes muy afiladas y ponerlas en la lanza hacen que esta arma multipliquesu velocidad, factor intrínseco, por una nueva capacidad, dada por el hierro, factor extrínseco. En otro sentido podemos citar las "no bárbaras estratagemas que usan los indios" (Gónzalez de N ájera, 1971: 97). Constatar la existencia de esta ciencia menor implica considerar, seriamente, la abolición de las tesis evolucionistas, esto es que los hombres llegaron al Estado como una forma superior de organización. La nomadología, en cambio, muestra que el nomadismo es una opción cuyo fin es precisamente conjurar la aparición del Estado. La sociedad nómada es "una sociedad contra-Estado" (D eleuzey G uattari, 1997: 366). De ahí que en su interior funcionen mecanismos colectivos de inhibición. M ecanismosqueG onzález deN ájera observa en los araucanos cuando éstos rehúsan congregarse en pueblos por razón quese dan venenos unos a otros. Ello a raíz de que el guerrero está "animado por una indisciplina fundamental, un perpetuo chantajeal abandono y a la traición... " (D eleuzey G uattari, 1997: 366), asunto que el texto constata: "Y pasan a nuestro bando a hacerse la guerra con toda crueldad, hermanosa hermanosy padresa hijos" (G ónzalez de N ájera, 1971: 48).

Por lo anterior se hace necesario aceptar que el desarrollo de los nómadas sólo es diferente. D e ahí que en el D esengaño... se perciba, a su pesar, la astucia y sagacidad del mapuche al enfrentar al invasor.

2. El segundo factor de roce para la máquina española es la gran fortal eza que los indios encuentran en su tierra, rasgo ya comentado a propósito del carácter nómada de la máquina india. 
3. El tercero es la incapacidad de los españoles para comprender su mayor error en el transcurso de la, pretendida, Conquista: "Todos han ignorado, a mi modo de ver en lo que ha estado el yerro y la falta de no poder acabar con esa hidra de siete cabezas" (G ónzalez de N ájera, 1971: 209). El yerro ha sido, fundamentalmente, el ir fundando ciudades sin una mayor protección: "Tan sin recelo comenzaron a fundar, no una ciudad siquiera, donde estuvieran todos juntos, sino muchas ciudades como allálas Ilaman, y tan divididas unas de otras" (Gónzalez de Nájera, 1971: 211). Esta distribución geográfica de las fuerzas del Estado provoca la debilidad y hace perder la ventaja real de la máquina española en las tierras de Arauco.

En base a lo anterior el astuto estatal que es don Alonso, confirma que era imposible dominar a los indios con el sistema imperantey proponeun regreso a las bases mismas que organizan el accionar del Estado. Es decir, replegarse, introducirse, a un espacio controlado, limitado. Por ello insta a los señores del Imperio a recoger "los fuertes desmandadosy perdidos y con ellosse haga una fuerte einexpugnablefrontera" (González deN ájera, 1971: 213)4. Esta es la forma ideada para recuperar la ventaja real de la máquina española, aquí se cifra el desengaño del Estado; leemos: "Y puestenemos armas defensivas y ofensivastan aventajadas a las de los indios... en que cien hombres bien armados acometen sin recelo a mil de los suyos... ¿por manera que siendo estas ventajas tan evidentes por quéno procuramostenerlas? Pues teniendo todas nuestrasfuerzas juntas..." (G onzález de Nájera, 1971: 255). Se confirma nuestra observación sobre la ofensa que significa equiparar la ventajateórica de la máquina de guerra araucana y la española para el D esengaño... Claramente vemos cómo el autor muestra que el problema, como ya se dijo, es otro, es estratégico. D e allí que anulada la versión sobre la igualdad teórica, proponga recuperar la ventaja real de la máquina española mediante el expediente de estriar el espacio, limitarlo. Luego, en Alonso G onzález de N ájera se concreta una vieja aspiración de todo funcionario: ser un pensador... "en efecto, ¿quéhombre de Estado no ha soñado con esa pequeña cosa imposible, ser un pensador?" (D eleuze y Guattari, 1997: 381). A hora este pensamiento deberá responder, en su estructura, al cogitatio universalis quelo anima, el que no es otro quela sumisión a una forma: "El pensamiento ya se ajustaría de por sí a un model o que toma prestado el aparato del Estado y que le marcaría fines, caminos, conductos, canales, órganos, todo un organon" (D eleuze y Guattari, 1997: 381). Veamos la frontera, el organ on:

\footnotetext{
${ }^{4}$ El destacado es nuestro.
} 
Demostración de los fuertes de la frontera con la guarnicion de in/antoria y caballeria que ha de tener cada uno.

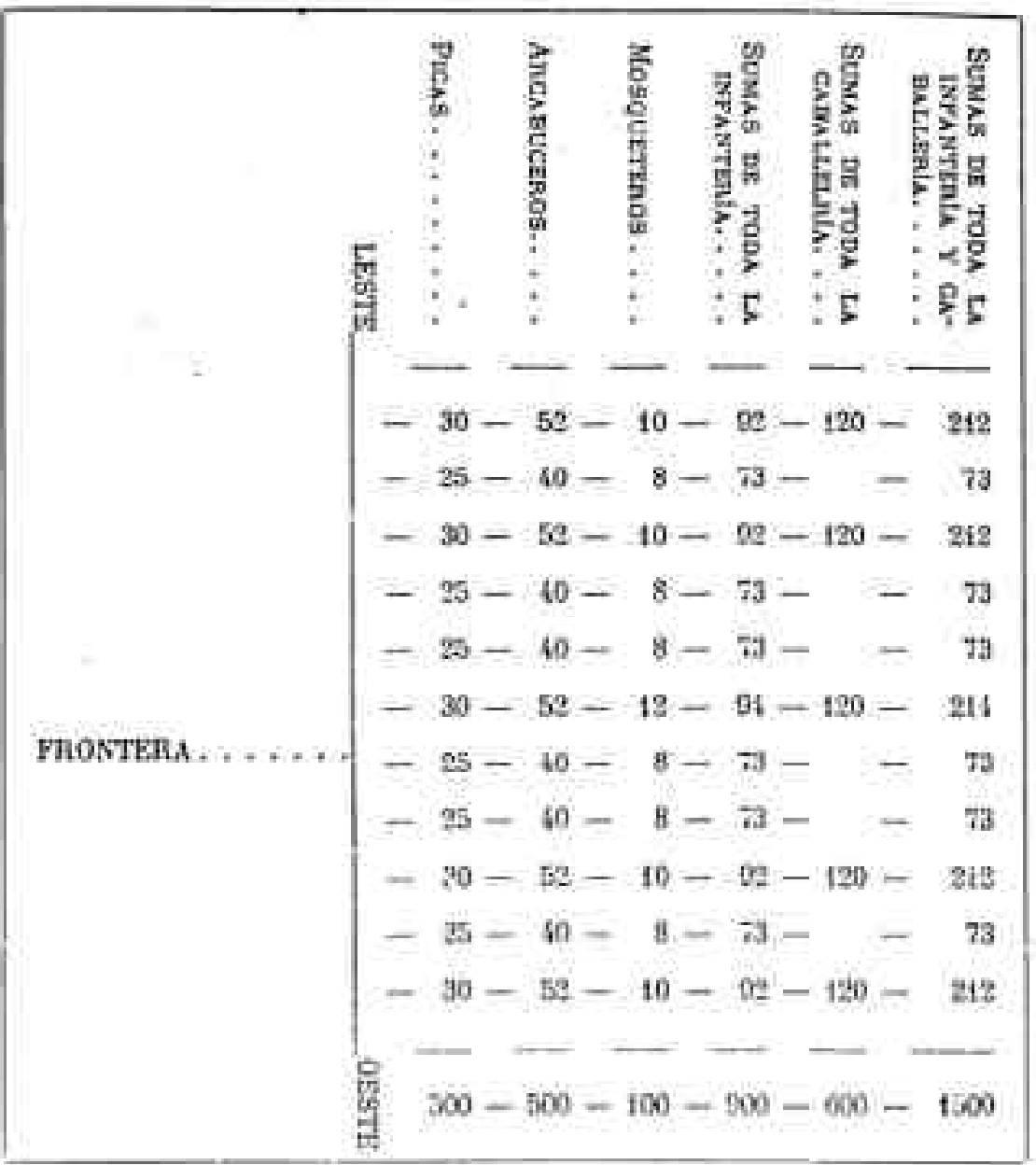

Fuente: González de Nájera, Alonso. D esengaño y reparo de la Guerras del Reino de Chile. Andrés Bello. Santiago de Chile. 1971, p. 233.

Se observa claramente que la propuesta del autor se pliega a los desarrollos propuestos sobre la forma de pensar producida por el Estado. Aún más, es típico de los sedentarios "distribuir a los hombres en un espacio cerrado, asignando a cada uno su parte..." (D eleuze y Guattari, 1997, 381). El pensador estatal trabaja en el mismo sentido al señalar cómo ha de distribuirse la guarnición en 
la "fuerte frontera", la cual debía estar ubicada en una zona angosta del Reino, a fin de ser cubierta en propiedad por los oncefuertes quela conforman, tal como se observa en el grabado.

La forma estatal de delimitar el espacio está basada en "un modelo hilomórfico... de distribución delas materias en franjas paralelas... " (D eleuzey Guattari, 1997: 375). Aquí en la frontera de G onzález de N ájera se plasma el organon que "sería algo así como la forma-estado marcada en el pensamiento" (D eleuze y Guattari, 1997: 3805), marca que no sólo consiste en estriar el espacio y limitar todo lo que se pueda al planeta y a sus habitantes, sino que además conlleva obscuras intenciones. Las que se muestran en el $D$ esengaño... a través de unas observaciones reveladoras: la primera es que se propone que una vez instalada la frontera se debe suprimir todo trato con los indios, pues en la época éstos comerciaban con los españoles, obtenían hierro de ellos ${ }^{6}$, etc. Luego, toda esa vecindad sólo ocasionaba problemas, ya que los mapuches conocían las debilidades y fortalezas de sus enemigos, por ello el autor sostiene que no debeexistir ningún vínculo, desde la instalación dela "fuertefrontera", con los “indios de la guerra".

La segunda es el plan para conquistar que tiene Alonso G onzález de N ájera, una suerte de solución final para el "problema araucano", consistente en que el territorio más allá de la frontera debía ser considerado un encierro para los indios. Los españoles se obligaban a ir haciendo una guerra ofensiva desde su frontera, guerra en que sólo corresponderá perdonar la vida a indios e indias no mayores de 16 años. A los sobrevivientes se les debería esclavizar y enviar, posteriormente, a otros territorios, como N ueva Granada, el Virreinato del Perú, etc. Luego se importarían negros, "más fáciles de cristianar", a la A raucanía y finalmente, cuando estuviesen dadas las condiciones, la tierra debía ser entregada a campesinos de Andalucía.

En este momento cabe una digresión: C reemos que el plantear una guerra ofensiva es lo que impidió que fructificase la propuesta de Nájera, pues los “humanistas" de la época habían logrado imponer el concepto de guerra defensiva en las Indias. D eahí, incluso queel manuscrito del D esengaño... fuese guardado en el Archivo de Simancas y dado a la imprenta sólo en la segunda mitad del siglo XIX.

Volviendo al punto, notamos que, desgraciadamente, el pensamiento estatal no sólo responde a una forma de expresión, el organon hilomórfico, sino que

\footnotetext{
${ }^{5}$ Como vemos, 0 ccidente ha llegado bastante cerca de nosotros, nos habita, determina el pensamiento, conoce, por ende, todos nuestros secretos.

${ }^{6} \mathrm{Al}$ respecto confróntese las relaciones de flujo entre nomadismo y metalurgia en D eleuzeGuattari, 1997, 405 y siguientes.
} 
también a una forma de contenido, pues todo aquello que no cabe en el cuadrado es la alteridad y ésta debe ser eliminada, confirmamos con el texto: "N o es otra cosa la guerra de Chile que una caza y montería de fieras" (Gónzalez de Nájera, 1971: 254).

Así pensaban los hombres del Estado hace cinco siglos. D eellos se defendieron los nómadas. Enfrentamiento entre una forma de pensar y una de vivir, que repite el antiguo conflicto entre "sociedades contra-Estado, llamadas primitivas y sociedades-con-Estado, Ilamadas monstruosas" (D eleuze y Guattari, 1997: 366). Dijimos que los nómadas evitan la aparición del Estado, ello debido a "un presentimiento demasiado misterioso de lo que conjuraban y no conocían" (D el euze-G uattari, 1997: 437. "A parato de captura"). Son capaces de percibir la monstruosidad de lo desconocido: El Estado, máquina de exclusiones, de dominio, de control, que plantea al hombrela disyuntiva de "habitar como poeta o como asesino. Asesino es aquel que bombardea al pueblo existente con poblaciones moleculares que no cesan de cerrar todos los agenciamientos, de precipitarlos en un agujero negro cada vez más profundo" (D eleuze y G uattari, 1997, 349. "D el Ritornelo"). Posición privilegiada de los pensadores estatales a este respecto, pues Estado se puede entender, también, como el "grado o modo de agregación de moléculas de un cuerpo" (D iccionario Encarta, 2000)7. Esto es exactamente lo que hace González de N ájera, agregar moléculas (arcabuces, caballos, infantes, picas, etc.) a un cuerpo, cerrándolo con una frontera, bombardeando desde allí a un pueblo existente, censurando todossusagenciamientos, precipitándolo en un agujero cada vez más amplio y profundo, el de la muerte fascista ${ }^{8}$

Recordemos ahora, que existe una alternativa frente al modelo estatal, ella es habitar el mundo como poeta, como nómada, liberando lo molecular con el fin de potenciar que "surjan fuerzas que pueden ser atribuidas al Cosmos..." (D eleuze-Guattari, 1997: 349. "D el Ritornelo"), momento en que la vida deja de ser pura inmovilidad molar y se transforma en puro devenir... "El devenir sería como la máquina, presente en cada agenciamiento, pero pasando del uno al otro, abriendo el uno al otro... " (D eleuze-Guattari, 1997, 351. "D el Ritornelo"), es decir, el encuentro con la alteridad no pasa por el exterminio, sino que por el

\footnotetext{
${ }^{7}$ Entrada número once del término.

${ }^{8}$ Sostenemos, a este respecto, queel encierro propuesto para someter a los araucanos no es otra cosa que un remoto antecedente de los campos de exterminio. Bellezas de la muerte que no son una desviación, una locura, de los nazis, sino que sólo muestran desnudo el atávico actuar de 0 ccidente. Belzec no es un accidente de la historia, es el infierno inmutable que espera a la alteridad.
} 
devenir para los seres de la exterioridad, entre los cuales se encuentran los nómadas, quienes, al parecer, no son tan bárbaros como los pintan $\mathrm{N}$ ájera y los suyos.

0 tros hombres del Estado, dificultosamente, fueron capaces de devenir nómadas, pensadores nómadas, ellos son los que habitaron como poetas durantela conquista de Chile, alisando el espacio del Reino, inaugurando de esta forma el encuentro con el otro, poblando así al mundo de un rumor benévolo. Caso ejemplar: Alonso de Ercilla.

\section{REFERENCIAS}

D eleuze, Gilles y Félix G uattari. 1997. M il mesetas. Valencia: PreTextos.

Diccionario Encarta. 2000. M icrosoft.

González de Nájera, Alonso. 1971. D esengaño y reparo de la guerras del Réno de Chile. Santiago de C hile: Andrés Bello.

Enciclopedia Encarta. 2000. M icrosoft.

Rodríguez, M ario. 2002. Curso "La máquina de guerra en los textos coloniales chilenos". Programa de D octorado en Literatura Latinoamericana. Universidad de Concepción (inédito). 